\title{
Hybrid DFIG Driven Wind Turbine - Grid Systems Modeling and Control for Reliable Source
}

\author{
Sally El-Tawab, Ibrahim Nassar, Mohammed Mehanna
}

\begin{abstract}
This paper proposes an approach for modeling the wind turbines and designing a control methodology. Look up table of the optimal power is achieved based on maximum power point tracking (MPPT) profile for maximizing system effectiveness. A $5 * 2 \mathrm{MW}$ and $690 \mathrm{~V}$ wind farm connected with IEEE 14 bus network is the suggested system. The wind energy conversion systems (WECS) are associated with the network through Voltage Source Converters (VSC). The doubly-fed induction generator (DFIG) is used, due to its ability to work at multiple operational speeds. DFIG vector control model is used for the system performance validation. Pitch angle control methodology is used for regulating the mechanical power at high wind velocity. The controller dynamic range for both wide speed changes and line faults is significantly achieved. An acceptable output power is obtained using this system for wide speed range. The MATLAB/Simulink software is used to construct a model of wind farm and the utilized public network.
\end{abstract}

Keywords: DFIG, grid side converter (GSC), rotor side converter (RSC), wind turbine modeling.

\section{INTRODUCTION}

To accomplish optimum integration of elevated wind energy interpenetration in the power system, the wind farms should be willing to substitute those certain conventional power station, i.e. the ability to sharing in the power systems stabilization and control. The major sequel of this paper is the wind farm verification model, which can use to analyze and improve the wind farm power plant characteristics [1]. In variable speed wind turbines, rotary rotor speeds are allowed to change as wind speeds change; this prevents asynchronous and synchronous generators from being used in these wind turbines when their output is directly linked to the network. This is where the doubly-fed induction generator (DFIG),

Manuscript published on November 30, 2019.

* Correspondence Author

Sally El-Tawab*, Department of Electrical Engineering, Faculty of Engineering, Al-Azhar University, Cairo, Egypt. Email: sally.eltawab@azhar.edu.eg

Ibrahim Nassar, Department of Electrical Engineering, Faculty of Engineering, Al-Azhar University, Cairo, Egypt. Email: ibrahim.nassar@azhar.edu.eg

Mohammed Mehanna, Department of Electrical Engineering, Faculty of Engineering, Al-Azhar University, Cairo, Egypt. Email: Mehanna2002@hotmail.com

(C) The Authors. Published by Blue Eyes Intelligence Engineering and Sciences Publication (BEIESP). This is an open access article under the CC-BY-NC-ND license http://creativecommons.org/licenses/by-nc-nd/4.0/ because it enables processing of the output frequency and the voltage of the generator at constant values, irrespective of the alternator rotor velocity (thus, regardless of wind speed).

For this motive, the ac current frequency $f_{\text {rotor }}$ fed into the rotor windings of DFIG (1), must be continuously adapted to confront any variation in the rotor speed $N_{r^{a}}$ which triggered by a change in the mechanical force of the primary mover which driving the generator and this is the task of the converter.

$$
f_{\text {rotor }}=f_{\text {grid }}-\frac{N_{r} * P}{60}
$$

Where $P$, $f_{\text {grid }}$ is the pair poles number and the ac power network frequency respectively.

As a result of doing that, the operation will be without sudden torque variations in the rotor of wind turbine, reducing the stress imposed on the wind turbine (mechanical parts) and smoothing the fluctuations in power which generated by the generator. In addition, the quantity of reactive power swapped between the generator and the grid is adjusted. [2].

The wind energy conversion system (WECS) dependent on the DFIGs model in a vectorized style in the synchronous reference frame, and an AC/DC/AC IGBT-depends on pulse width modulation (PWM) converter. Moreover, its control contains both the rotor side converter (RSC) which encompasses the technique of the maximum power point tracking (MPPT) method and the grid side converter (GSC) controllers. RSC controls the stator's reactive and active powers, GSC is to maintain the dc-link voltage constant value irrespective of the size and Power direction of the rotor and to regulate the reactive power that is exchanged with the ac power network [3].

\section{WIND TURBINE MODELING}

The capture of kinetic energy which exists in the wind and converts it to electrical power is the purpose of wind turbine design. From the point of perspective of modeling, the wind turbines components and the interaction between them shown in Fig.1, [4]: 


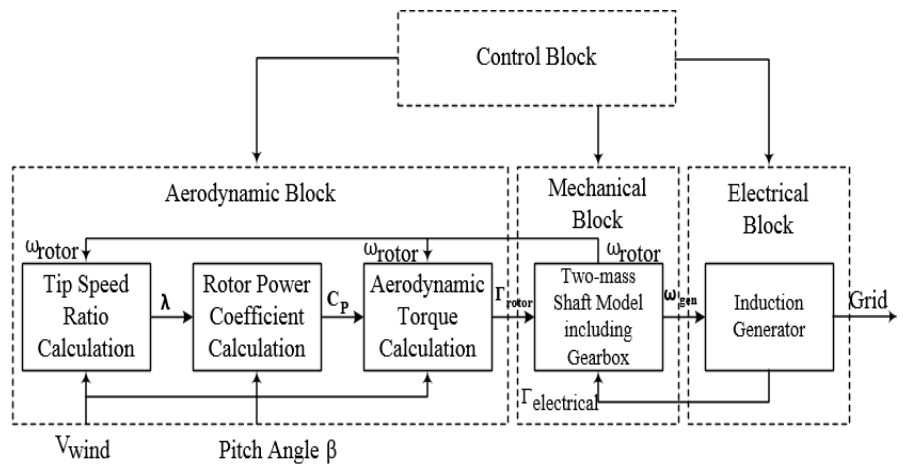

Fig. 1.Planning of the airstream Turbine System modeling.

\section{A. Aerodynamic Block}

The wind power, $P_{\text {wind }}$ is the time-derivative of its kinetic energy (2). Where, $A$ is area overrun by the blades of the rotor, $P$ is the air density and ${ }^{v}$ is speed of wind [1]. This is the complete energy available for extraction.

$$
P_{\text {wind }}=.5 \rho A v^{a}
$$

Betz showed that the highest energy extracted by an optimal turbine rotor with endless wind blades and with optimal circumstances is $59.26 \%$ of wind energy; this limit is defined by the Betz limit. In fact, wind turbine blades are restricted to 2 or 3 blades as a result of economic considerations and a range of structural, so the quantity of energy that we can captured it is approaching about $50 \%$ of the accessible energy [5].

The power extracted ratio to available power is given as the rotor power coefficient $C_{\mathrm{p}}$. The power extracted can be given as:

$$
P_{\text {rotor }}=.5 \rho A v^{2} C_{p}\left(\lambda_{s} \beta\right)
$$

The $C_{\mathrm{p}}$ is a highly non-linear function of the tip speed ratio $(\lambda)$ which is defined as the ratio of the blade-tip speed in linear form to the wind speed and the blade pitch angle $\beta$.

$$
\begin{aligned}
& \lambda=\frac{v_{\text {rfy }}}{v_{\text {wefid }}}=\omega_{T} * R / v \\
& C_{p}\left(\lambda_{s} \beta\right)=C_{1}\left(\frac{C_{2}}{\lambda_{i}}-C_{a} \cdot \beta-C_{4}\right) \cdot e^{-\frac{C_{5}}{\lambda_{i}}}+C_{6} \cdot \lambda \\
& \frac{1}{\lambda_{1}}=\frac{1}{\lambda+0.08 \beta}-\frac{0.035}{\beta^{3}+1}
\end{aligned}
$$

Where $R$ is the radius overrun by the blades of the rotor, $\omega_{T}$ is the rotor wind turbine velocity and the coefficients $C_{1}$ to $C_{6}$ are: $C_{1}=0.5176, C_{2}=116, C_{a}=0.4, C_{4}$ $=5, C_{5=21}$ and $C_{6}=0.0068$ [6]. Fig. 2, displayed ${ }^{C_{\mathrm{p}}}$ with the variation of $\lambda$ and $\beta$.

Then we can calculate the aerodynamic torque $(\mathrm{Nm})$ as:

$$
T_{T}=\frac{P_{\text {rotor }}}{\omega_{T}}=\frac{0.5 \rho A v^{3} C_{V}}{\omega_{T}}
$$

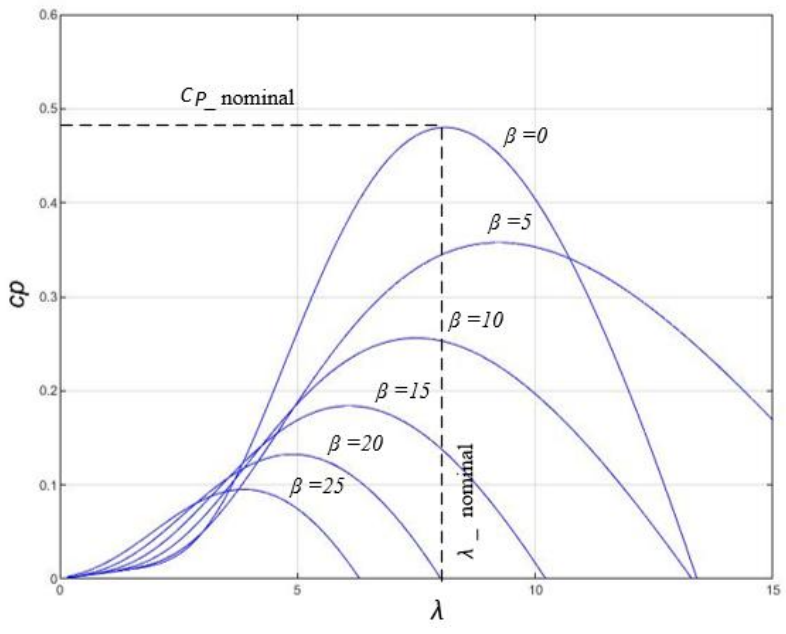

Fig. 2.The $C_{p}-\lambda$ characteristics.

\section{B. Mechanical Drivetrain}

For drive train, models there are four types that are normally available in the power system analysis, Six, Three, Two and lumped model (One-mass). The common and acceptable technique of modeling a wind turbine's drive train for analyzing the operation of the power system depends on assuming only two lumped/masses: the hub with blades (wind wheel) mass and the generator (with gearbox) mass [7].

Fig.3, shows the wind turbine rotor's aerodynamic torque $\mathrm{T}_{T}$ and the electromechanical torque $\mathrm{T}_{G}$ from the direct-connection with induction generator, working against to one another. The equations of torque with all amounts referred to the generator side can be written as:

$$
\begin{aligned}
& l_{T} \theta_{T}+D\left(\omega_{T}-\omega_{r}\right)+K\left(\theta_{T}-\theta_{r}\right)=\mathrm{T}_{T} \\
& l_{G} \theta_{r}+D\left(\omega_{r}-\omega_{T}\right)+K\left(\theta_{r}-\theta_{T}\right)=-\mathrm{T}_{G}
\end{aligned}
$$

Where $I_{T_{a}} J_{G} \quad$ Moments of inertia of the rotor for the wind turbine and the generator $\left(\mathrm{kgm}^{2}\right)$.

$\omega_{y}$ Generator velocity (rad/s).

$\theta_{T}, \theta_{r} \quad$ Angular position for the rotor of the wind turbine and the generator (rad).

$D, K$ Damping and stiffness equivalent (Nm.s/rad), (Nm/rad) respectively.

Using some simplification assumptions, the stiffness of the drivetrain is infinite and the inertia and friction factor of the turbine amalgamated with those of the generator that associated with the turbine. The mechanic's equation of the rotor is a great importance in studying of stability of the power system as it explains the impact of any aerodynamic torque inconsistency, and the electromagnetic machine torque. The mechanic's equation of the rotor can be written as:

$$
l_{\text {total }} p \omega_{y}=\mathrm{T}_{T}-\mathrm{T}_{G}-\mathrm{T}_{F}
$$

Where $l_{\text {total }}$ is the generator and the turbine moment of inertia combined with each other $\left(\mathrm{kgm}^{2}\right)$,

Published By:

Blue Eyes Intelligence Engineering

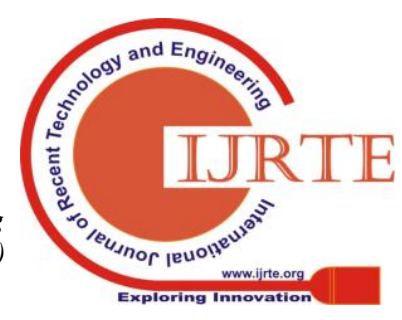




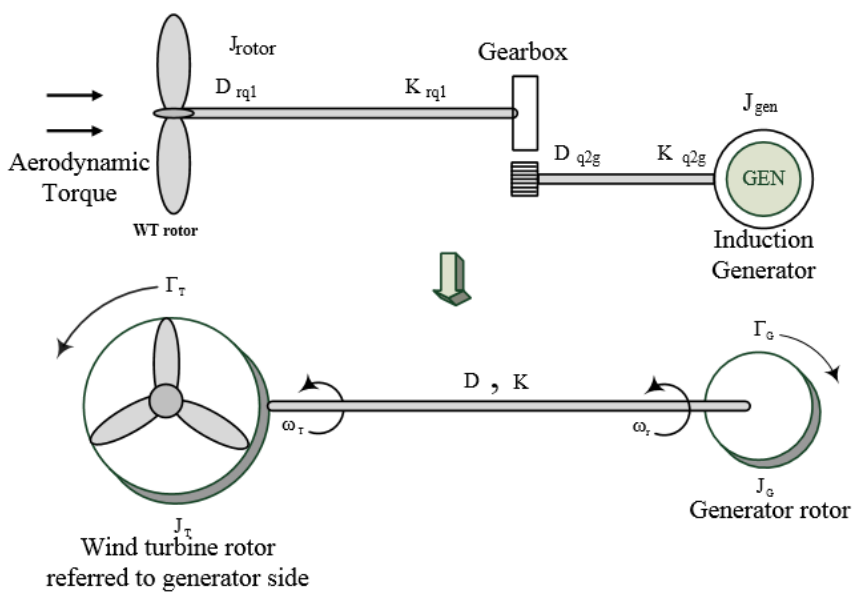

Fig. 3.Modeling of wind turbine drive trains.

$p$ is $d / d t$ and $\mathrm{T}_{F}$ is the combined friction torque. Equation (10) can be normalized in terms of the inertia constant $\mathrm{H}$ (the per-unit).

$$
p \omega_{Y}=\frac{1}{2 \mathrm{H}}\left(\mathrm{T}_{T}-\mathrm{T}_{G}-\mathrm{T}_{F}\right)
$$

\section{The Generator Modeling}

DFIG is a wound-rotor induction machine. Generally, the rotor circuit is accessed by brushes and slip rings. The three-phase winding of the stator is directly linked to the grid, which is typically less than one $\mathrm{kV}$ at the power system frequency $(50 / 60 \mathrm{~Hz})$ as displayed in Fig.4.

In the rotating $\mathrm{d}-\mathrm{q}$ reference frame, DFIG's electrical equations are written as follows:

- Equations of the stator voltage:

$$
\begin{aligned}
& V_{q s}=R_{g} i_{q s}+\omega_{s} \psi_{d s}+p \cdot \psi_{q s} \\
& V_{d s}=R_{g} i_{d s}-\omega_{s} \psi_{q s}+p \cdot \psi_{d s}
\end{aligned}
$$

- Equations of the rotor voltage:

$$
\begin{aligned}
& V_{q y}=R_{y} i_{q y}+\left(\omega_{g}-\omega_{y}\right) \cdot \psi_{d y}+p \cdot \psi_{q y} \\
& V_{d y}=R_{y} i_{d y}+\left(\omega_{g}-\omega_{y}\right) \cdot \psi_{q y}+p \cdot \psi_{d y}
\end{aligned}
$$

- Equations of the stator flux:

$$
\begin{aligned}
& \psi_{q g}=L_{g s} i_{q s}+L_{M} i_{q r} \\
& \psi_{d g}=L_{g s} i_{d g}+L_{M} i_{d r}
\end{aligned}
$$

- Equations of the rotor flux:

$$
\begin{aligned}
& \psi_{q y}=L_{y}, i_{q y}+L_{M v} i_{q s} \\
& \psi_{d y}=L_{y}, i_{d y}+L_{M r} \cdot i_{d s}
\end{aligned}
$$

Where: $L_{s}=L_{\rrbracket s}+L_{M}, L_{y}=L_{\mathbb{}}+L_{M}$

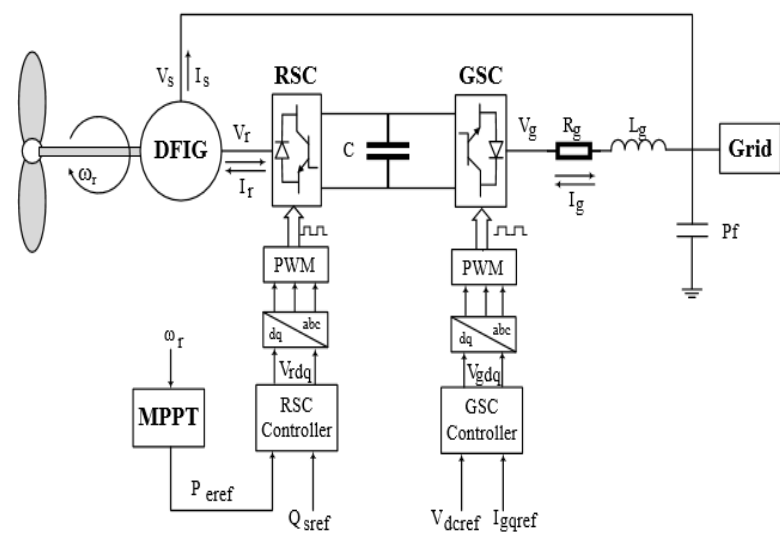

Fig. 4.Configuration of a DFIG connected to the network in the wind turbine system.

In these equations $R_{s}, R_{r}, L_{i s}$ and $L_{i r}$ are the resistances and leakage inductances of the stator and rotor windings respectively, $L_{M}$ is mutual inductance. $V_{d s}, V_{q s}$, $V_{d r}, V_{q r}, i_{d s}, i_{q s}, i_{d r}, i_{q r}, \psi_{d s}, \psi_{q s}, \psi_{d r}$ and $\psi_{q r}$ are the direct and quadrature components of the stator and rotor voltages, currents and flux respectively [4].

- Stator's real and reactive power:

$$
\begin{aligned}
& P_{s}=3 / 2\left(V_{d g} \cdot i_{d g}+V_{q g} \cdot i_{q g}\right) \\
& Q_{s}=3 / 2\left(V_{q g} \cdot i_{d g}-V_{d g} \cdot i_{q g}\right)
\end{aligned}
$$

- Rotor's real and reactive power:

$$
\begin{aligned}
& P_{Y}=3 / 2\left(V_{d y} \cdot i_{d y}+V_{q r} \cdot i_{q V}\right) \\
& Q_{r}=3 / 2\left(V_{q r} \cdot i_{d r}-V_{d r} \cdot i_{q V}\right)
\end{aligned}
$$

- The electromagnetic torque:

$$
T_{e m}=3 / 2 * P *\left(\psi_{d g} i_{q s}-\psi_{q g} * i_{d g}\right)
$$

\section{MODELING OF BACK-TO- BACK AC/DC/AC CONVERTERRE}

There are different types of models to realize the Mathematical modeling of the converter system. One of these types is mathematical functional that explains the relationship among the system input and output signal in form of mathematical function [8], and it is used in this paper. To model the back-to-back PWM converters in the easiest scenario, it is presumed that the voltage of the DC-link is constant and the converters are ideal. Consequently, based on the control of the converter the operation of the RSC in the model can be displayed by a controllable VSC. The average terminal output voltage $V_{\text {out }}$ is given by:

$$
V_{\text {out }}=M * V_{d e}
$$

Where ${ }^{M}$ is the modulation index (must be between 0 and 1 ). $M$ be able to be varied in time therefore, any required frequency and voltage can be produced at the output terminals [9].

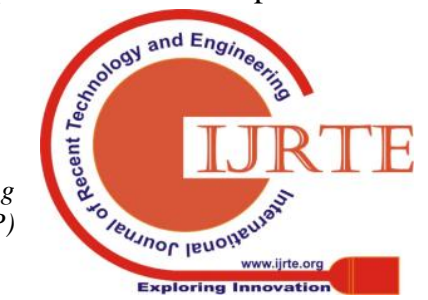




\section{Hybrid DFIG Driven Wind Turbine - Grid Systems Modeling and Control for Reliable Source}

\section{DEDIGN THE CONTROL SYSTEM}

The AC/DC/AC converter has two converters, the first is associated with the grid side (GSC) and the second is associated with the rotor side (RSC). The regulation of the two converters is discussed below.

\section{A. RSC Control System}

As in Fig. 5, the control of the RSC comprises of two control loops in cascaded form [10]:

- The internal current control loops adjust the rotor current elements of the q-d-axis separately.

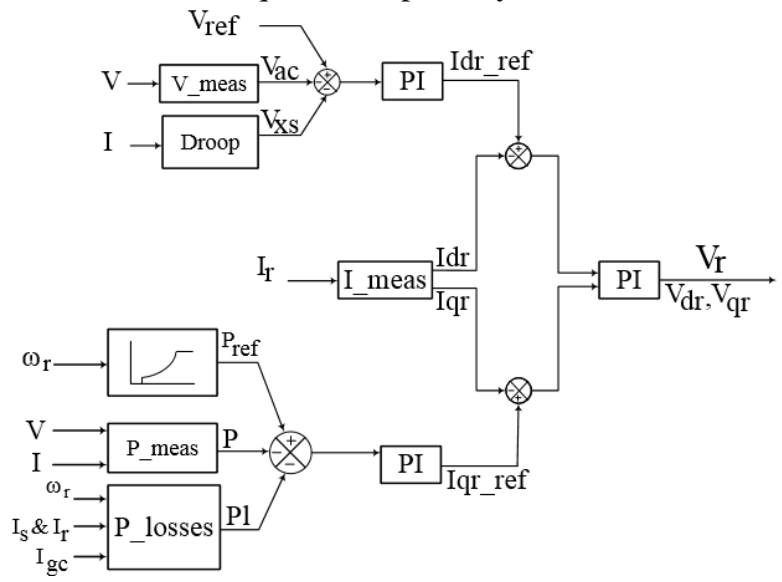

Fig. 5. Scheme of control of (RSC)

- The external control loops independently regulate both stator's real and reactive power.

If we allow the reference frame's d-axis to be oriented find that it aligns with the stator flux $\left(\psi_{d s}=\psi_{s}\right.$, and $\psi_{q s}=0$ ). With negligence the resistance $R_{s}$, voltages and fluxes of stator can be written as [11]:

$V_{d s}=0 \& V_{q s}=V_{s}=\omega_{g} * \psi_{d s}=\omega_{g} * \psi_{s}$

$\psi_{d s}=\psi_{s}=L_{g} i_{d s}+L_{M}, i_{d y} \& \psi_{d y}=L_{y} i_{d y}+L_{M} \cdot i_{d s}$

$\psi_{q S}=0=L_{g} i_{q S}+L_{M} \cdot i_{q Y} \& \psi_{q Y}=L_{y} i_{q Y}+L_{M} \cdot i_{q g}$

The stator currents of the q- and d-axis are provided by:

$$
\begin{aligned}
& i_{q s}=-\frac{L_{M}}{L_{s}} * i_{q r} \\
& i_{d s}=\frac{i_{m s}-i_{d v}}{L_{s}} * L_{M}
\end{aligned}
$$

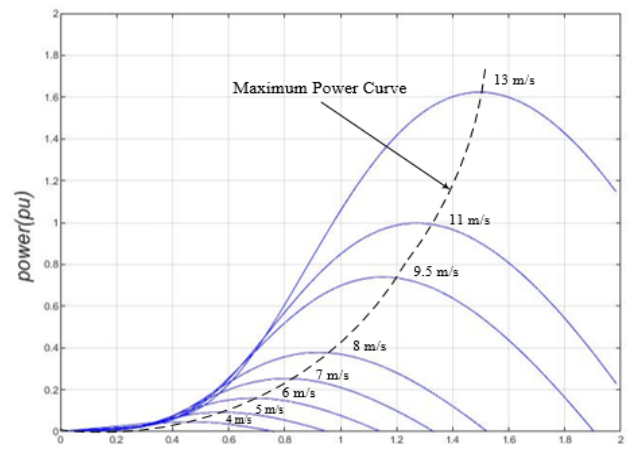

Angular speed $\mathrm{Wt}(\mathrm{pu})$

(a)
According to the rotor currents, the stator's real and reactive power can be written as:

$$
\begin{aligned}
& P_{g}=-\frac{a}{2} \frac{L_{M}}{L_{s}} V_{s} i_{Q V} \\
& Q_{s}=\frac{V_{s} \psi_{s}}{L_{s}}-\frac{V_{s} L_{M}}{L_{s}} i_{d V}
\end{aligned}
$$

The voltages can be written for the rotor according to the rotor currents as follow:

$$
\begin{aligned}
& V_{d y}=R_{y} i_{d y}+\sigma L_{y} p i_{d y}-s \omega_{g} \sigma L_{y} i_{q r} \\
& V_{q r}=R_{r} i_{q r}+\sigma L_{r} p i_{q r}+s \omega_{s}\left(\sigma L_{r} i_{d r}+\frac{\mathbb{I}_{Y g}^{2}}{\mathbb{L}_{s}} i_{m s}\right) \\
& i_{m s}=\frac{V_{q S}-R_{s} i_{g s}}{\omega_{s} I_{M}} \\
& \sigma=1-\frac{L_{M}^{2}}{L_{s} L_{T}} \\
& s=\frac{\omega_{s}-\omega_{Y}}{\omega_{x}}
\end{aligned}
$$

Equations (31), (32) obviously demonstrate the stator real and reactive power can be regulated separately by controlling the components of rotor current ${ }^{i_{q r}}$ and $i_{d r}$ respectively. The reference of q-and d-axis rotor currents is created from exterior power control loops by supplying the effective and reactive power (voltage) mistake to PI controllers.

Fig.6.a, illustrates how the Optimum energy extraction-speed curve designed to cross $C_{p \max }$ points for each wind speed with normal wind turbine. The maximum power curve $P_{\text {optimal selects maximum capture power and }}$ the control aim is to maintain turbines on this curve with varying the speed of wind. Fig. 6.b, shows the complete generator power speed characteristic named MPPT characteristic, which is performed by a look-up table for the controller model. The locus of $P_{\text {optimal }}$ curve is from point $\mathrm{B}$ to point $\mathrm{C}$ and due to the ratings of the power converter we are virtually unable to keep optimal wind speeds for power production. Therefore, the tracking characteristic is a straight line for very low wind speeds i.e. from point A to point $B$ with positive slope, similarly for high wind speeds from point $\mathrm{C}$ to point $\mathrm{D}$ [12]. The power for speed at point $\mathrm{D}$ is one per unit $(1 \mathrm{Pu})$ and after this point the reference power is remaining constant equal to $1 \mathrm{Pu}$.

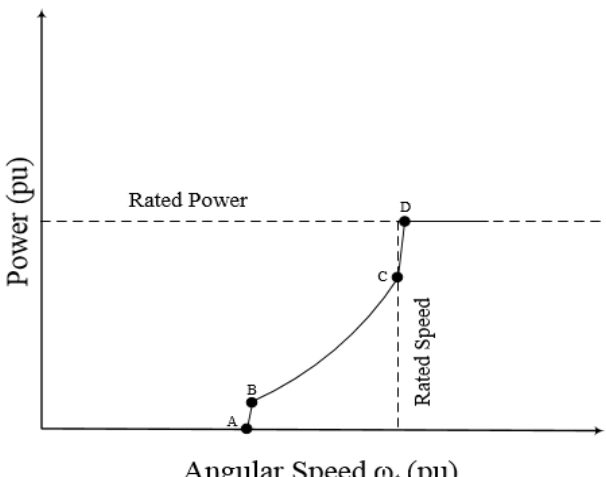

(b)

Fig. 6. (a)Characteristic of Wind turbine at variable speed, ( b) MPPT.

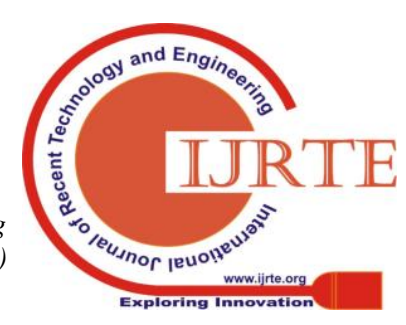


Through the reactive power absorbed or generated by the RSC, the voltage can be controlled at network terminals. The control of wind turbine applies the V-I characteristic as shown in Fig.7, which keeps the voltage is controlled at the reference voltage $V_{\text {ref }}$, so long as the reactive current remains within the values of the maximum current (-Imax, Imax) enjoined by the converter's rating [10].

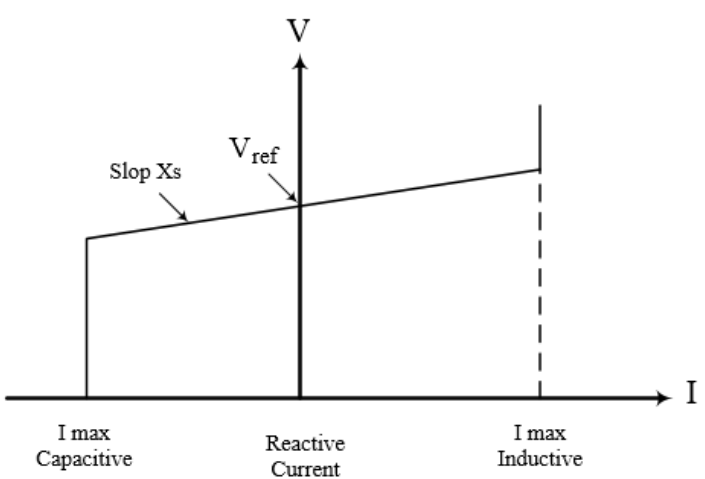

Fig. 7.V-I Characteristic

$$
V=V_{\text {ref }}+I * X_{g}
$$

Where ${ }^{V}$ is the positive sequence voltage, ${ }^{I}$ the reactive current and $X_{s}$ the slope or reactance droop.

\section{GSC CONTROL SYSTEM}

The inductance and resistance $\left(R_{g}, L_{g}\right)$ for a power filter as shown in Fig.4, is used to decrease the current harmonics which stream into the power source is taken into account:

$V_{d g}=R_{g} i_{d g}+L_{g} \times p i_{d g}-\omega_{g} L_{g} \times i_{q g}+V_{g}$

$V_{q g}=R_{g} \times i_{q g}+L_{g} \times p i_{q g}+\omega_{g} \times L_{g} \times i_{d g}$

For the GSC controller, the synchronous reference frame's d-axis is aligned with the positive sequence of network voltage $\left(V_{q g}=0, V_{d g}=V_{g}\right)$. $V_{d g}$ and $V_{q g}$ can be generated from the following feedback loops and PI controllers:

$V_{d g}=\left(K_{p g}+\frac{K_{\text {ig }}}{g}\right)\left(i_{d g}^{*}-i_{d g}\right)-\omega_{g} L_{g} \cdot i_{q g}+V_{g}$

$V_{q g}=\left(K_{p g}+\frac{K_{i g}}{g}\right)\left(i_{q g}^{*}-i_{q g}\right)+\omega_{g} L_{g} \times i_{d g}$

The reference current $\dot{i}_{d g}^{*}$ is the DC voltage controller output $\left({ }^{i} d g=\right.$ current in phase with the network voltage that regulates the real power flow). To design the Dc-link Voltage Controller, we will neglect the losses and the harmonics which coming from the switching in the GSC, the transformer and the filtering inductor. The quantity of energy stored in the dc-link condenser can be written as:

$$
E_{c}=\int P_{\text {net }} d t=\frac{1}{2} C \cdot V_{d c}{ }^{2}
$$

Where $P_{\text {net }}$ is the net power flow into the capacitor, $C$ is the dc-link capacitor value and $V_{d c}$ is the capacitor voltage.

$$
P_{\text {net }}=P_{r}-P_{g}
$$

Where $P_{\mathscr{r}}$ is The rotor's power inflow and $P_{g}$ is the power of the grid outflow. Derivative of (43) can be written as:

$$
\frac{d V_{d c}}{d t}=\frac{P_{\text {nat }}}{C \cdot V_{d c}}=\frac{P_{y}-P_{g}}{C \cdot V_{d r}} .
$$

Since:

$$
P_{g}=\frac{a}{2} V_{d g} \cdot i_{d g}=\frac{a}{2} V_{g} \cdot i_{d g}
$$

Thus, PI controller and a feedback loop can be designed to produce the reference value of d-axis current ${ }^{i_{d g}^{*}}$ as follows:

$$
i_{d g}^{*}=\left(K_{p v}+\frac{K_{i v}}{g}\right)\left(V_{d e}^{*}-V_{d c}\right)
$$

The value for the capacitance of the DC link is based on the wind turbine-DFIG rating and the nominal voltage of the DC link. [10]. The corresponding capacitance is .0095 farads and The DC link nominal voltage is $1380 \mathrm{~V}$.

The reactive power which exchanged among the network and the GSC is provided by:

$$
Q_{g}=-\frac{a}{2} V_{d g} \times i_{q g}=-\frac{a}{2} V_{g} \cdot i_{q g}
$$

Consequently, the reference value for $i_{q g}$ can be determined directly from the reactive power ordered [13].

\section{THE CONTROL SYSTEM OF PITCH ANGLE}

The controller of $\beta$ is only activated at high wind velocity. In these cases, it is no longer possible to control the rotor speed within its limits by increasing the generating power, which causes the appearance of overloads of the generator and/or the converter. Thus, the blade $\beta$ is regulated to decrease the mechanical power, which the turbine captured it from the wind, and then to avoid over-speed of the wind turbine generator. The blade $\beta$ is maintained at zero degrees until the wind velocity meets point $\mathrm{D}$ of the MPPT characteristic Fig.6.b. After this point, the pitch angle is proportional to velocity deviation from the velocity at point $\mathrm{D}$ as shown in Fig.8.

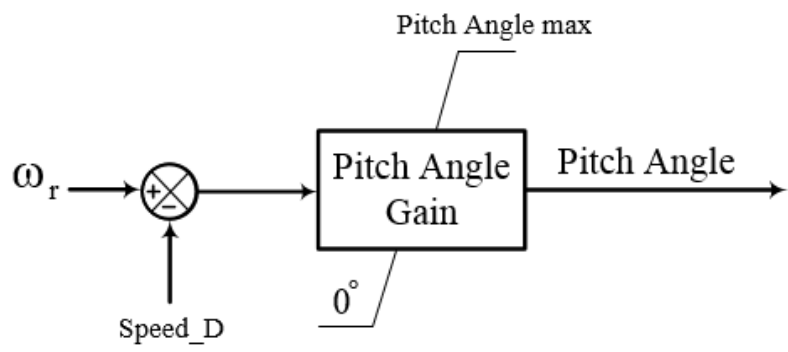

Fig. 8. The ${ }^{\beta}$ Controller

\section{SIMULATION MODEL}

To verify and compare the proposed system (wind farm $10 \mathrm{MW}$ integrated with the grid), the simulink model is implemented in a phasor type, where allowed transient stability studies with long simulation times. Fig. 9, shows wind turbine system simulink model.

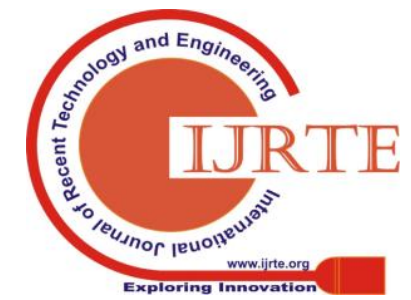




\section{Hybrid DFIG Driven Wind Turbine - Grid Systems Modeling and Control for Reliable Source}

- Case study

The wind farm is connected to IEEE 14 bus system [14] by external bus (bus 15) as presented in the simulink model in Fig.10. This research studies two cases which approved the robustness of a suggested model and success of the control process as required. The wind farm can be portrayed either as a PV bus with adequate VAR constraints or as a PQ bus with constant power factor [15]. In this paper, DFIG has been modelled as PV-bus due to its capability to keep a constant voltage at the interface point (bus 8) with the utility.

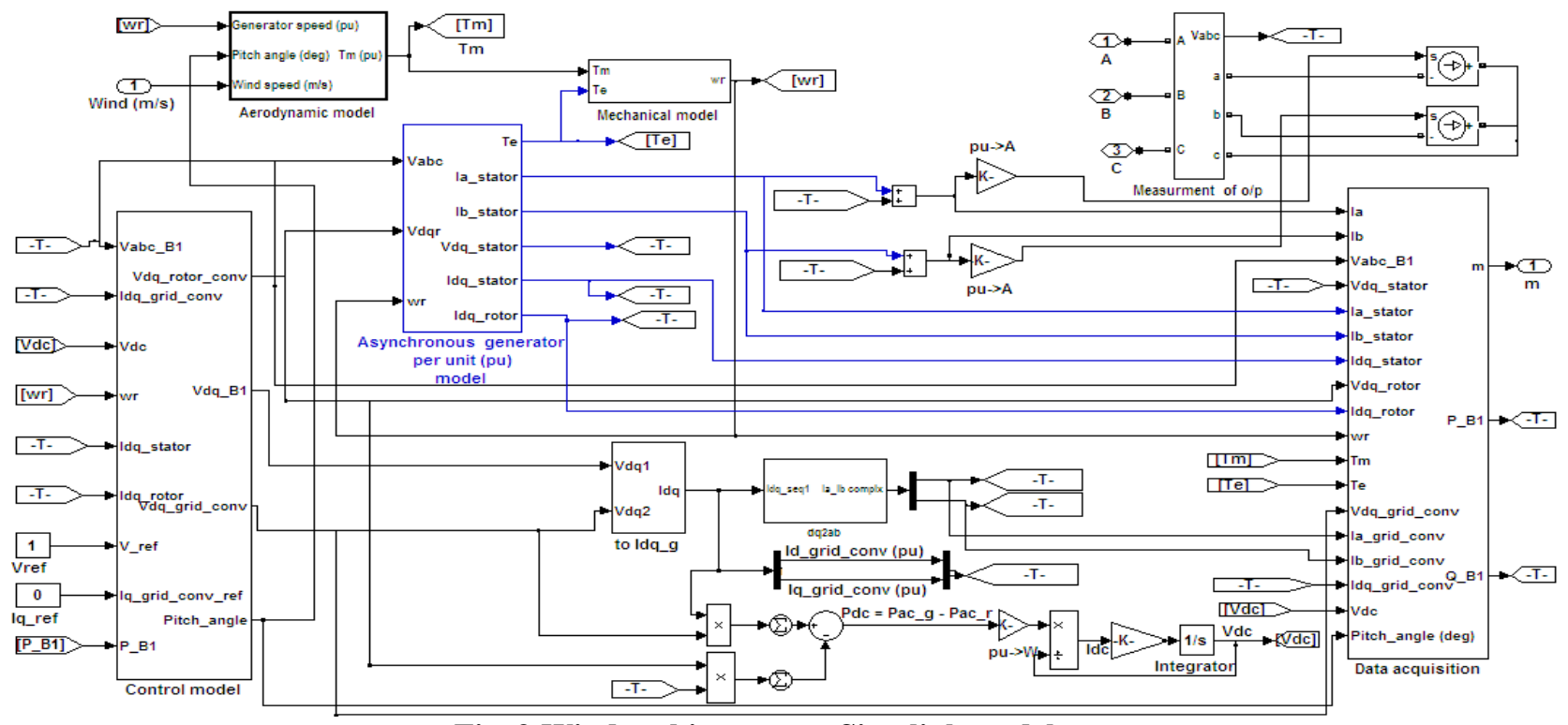

Fig. 9.Wind turbine system Simulink model.

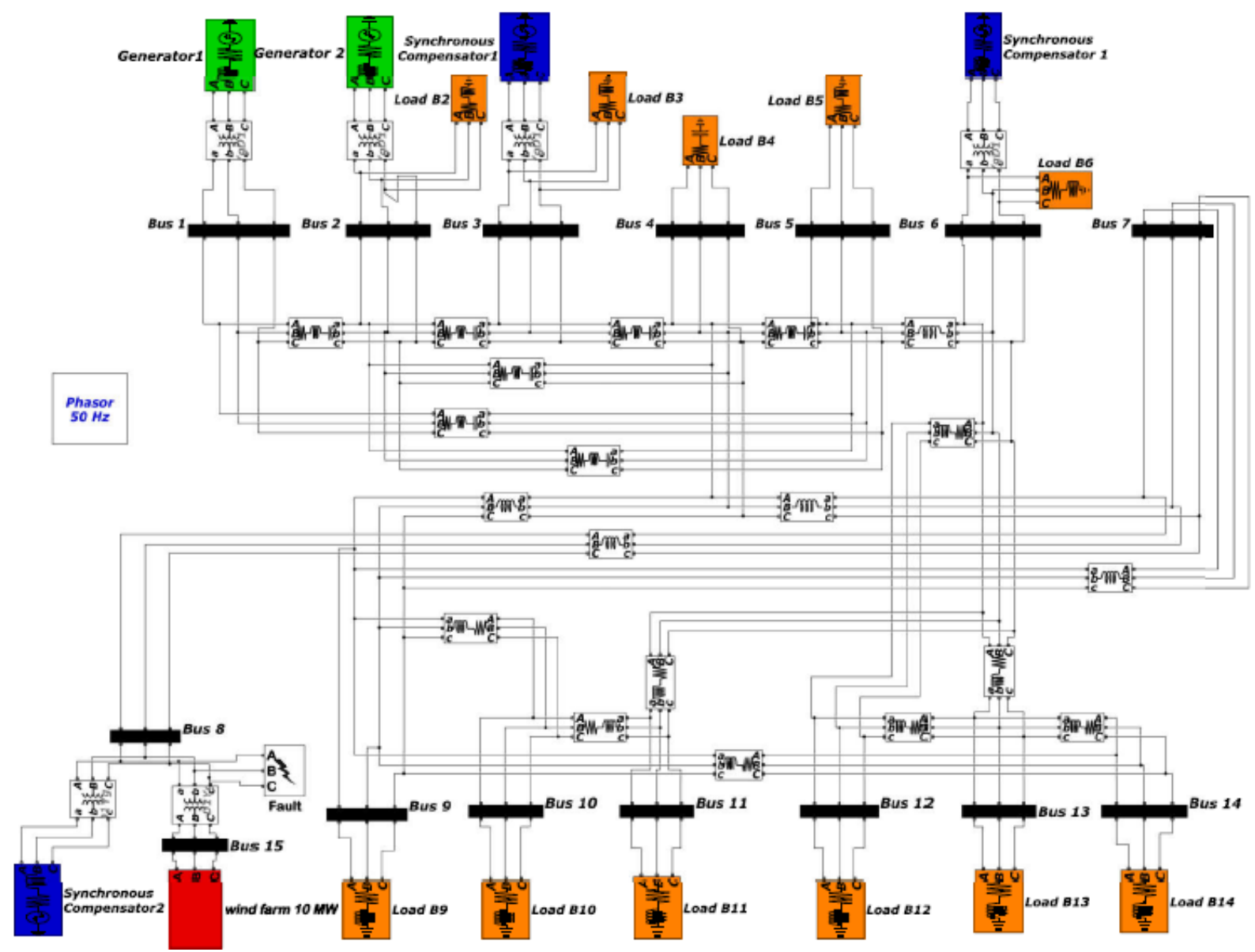

Fig. 10. Simulink model for Wind Farm connected to IEEE 14 bus system.

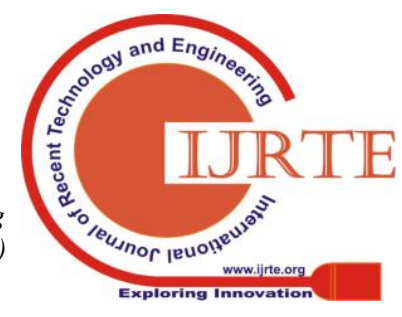




\section{RESULT AND DISCUSSION}

\section{A. Turbine response to wind Speed change}

In this simulation, the wind velocity is supposed to randomly change as shown in Fig.11.a, from $6 \mathrm{~m} / \mathrm{s}$ to $16.5 \mathrm{~m} / \mathrm{s}$.

Fig.11.b, shows the smoothly increasing of active generated power to reach its rated value of $10 \mathrm{MW}$ approximately, and then at $\mathrm{t}=32.4 \mathrm{~s}$ the speed is dropped and the power go back to tracking MPPT.

Rotor turbine velocity is increasing from $0.8 \mathrm{Pu}$ to $1.21 \mathrm{Pu}$ and at $\mathrm{t}=40.5 \mathrm{~s}$ start to increase responded to increasing of wind speed but back to $1.21 \mathrm{pu}$ by pitch angle controller as monitored in Fig.11. c.

Initially, the pitch angle is zero degree and the turbine operating point follows the tracking characteristic up to point $\mathrm{D}$, the pitch angle is increased at $\mathrm{t}=28.2 \mathrm{~s}$ and $\mathrm{t}=40.5 \mathrm{~s}$ from 0 deg to 0.725 deg and from 0 deg to 22.5 deg respectively, to limit the mechanical power as demonstrated in Fig.11. d.

The wind turbine generated and absorbed MVAR to regulate the voltage at $1 \mathrm{pu}$ as depicted in Fig.11.e, and Fig. 11.f respectively. DC- link output voltage is preserved constant $(1380 \mathrm{~V})$ as illustrated in Fig.11. g.

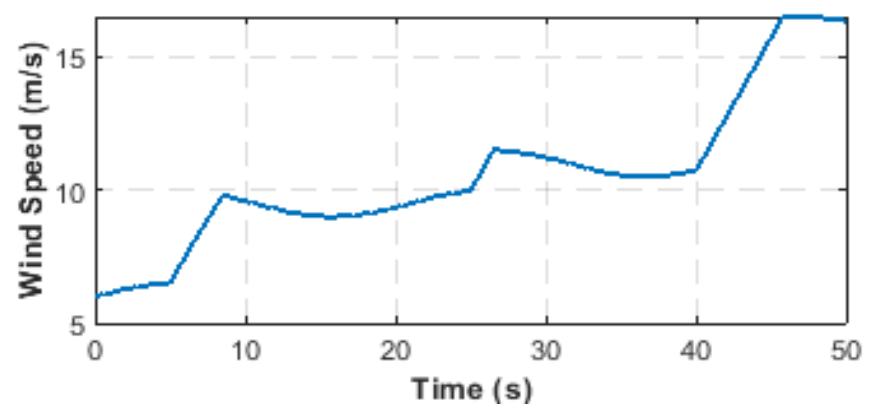

(a)

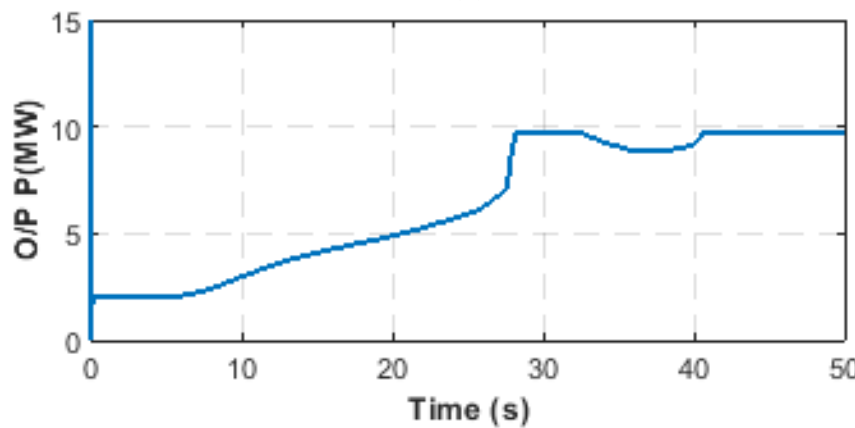

(b)

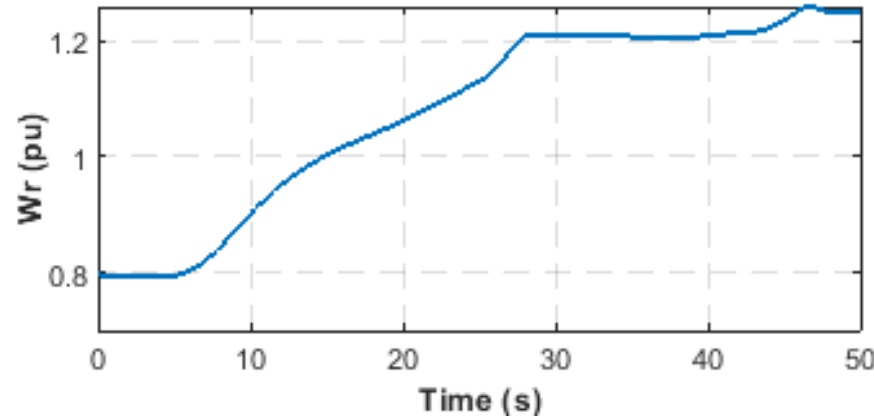

(c)

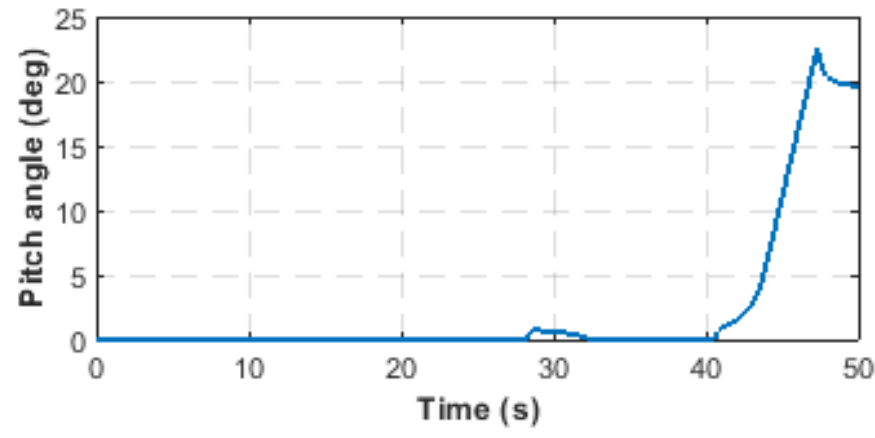

(d)

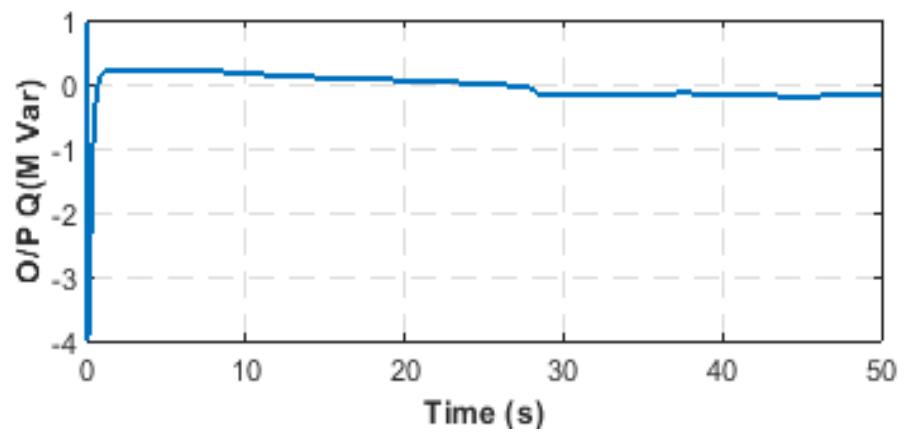

(e)

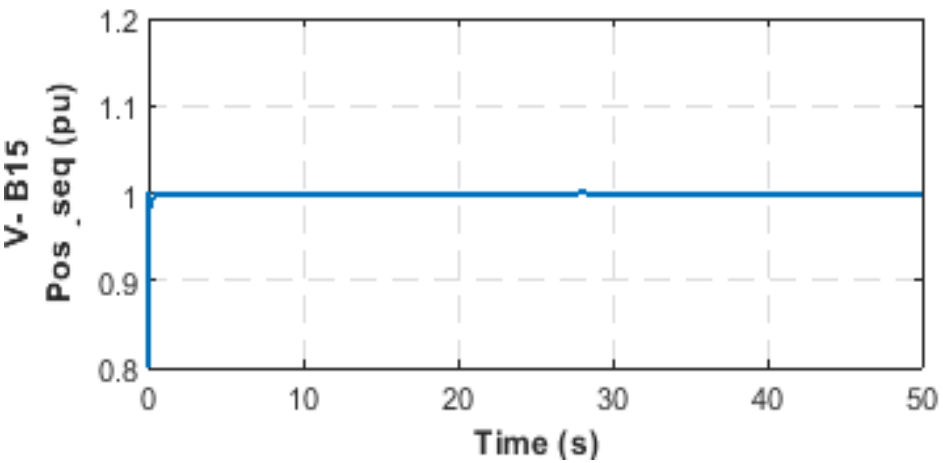

(f)

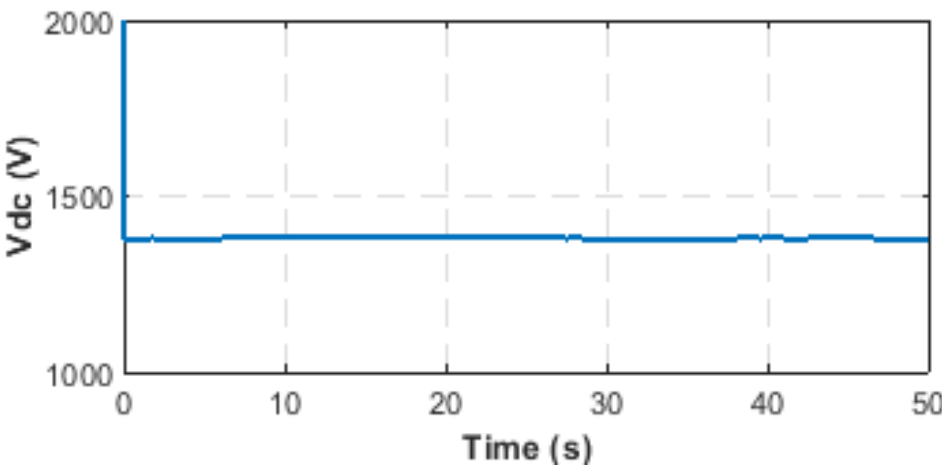

(g)

Fig. 11. Turbine response to a change in velocity:(a) wind speed, (b) the power, (c)wr, (d) pitch angle, (e) the reactive power, (f)the voltage, (g) vdc.

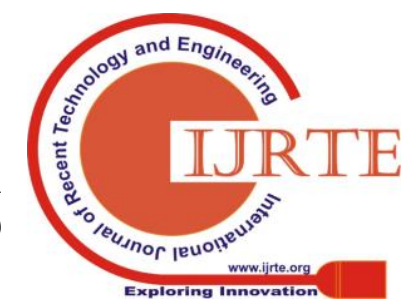




\section{Hybrid DFIG Driven Wind Turbine - Grid Systems Modeling and Control for Reliable Source}

Table - I is compared the mean value for the voltage profile at each bus before and after connected the wind farm with the grid.

Table- I: The positive sequance valtag comparson for IEEE 14 bus system

\begin{tabular}{|c|c|c|}
\hline Bus & V(pu) before & $V(p u)$ after \\
\hline 1 & 1.0120 & 1.0188 \\
\hline 2 & 1.0045 & 1.0117 \\
\hline 3 & 0.9782 & 0.9849 \\
\hline 4 & 0.9905 & 1.0005 \\
\hline 5 & 0.9954 & 1.0043 \\
\hline 6 & 0.9975 & 1.0047 \\
\hline 7 & 0.9938 & 1.0048 \\
\hline 8 & 0.9839 & 0.9988 \\
\hline 9 & 0.9814 & 0.9932 \\
\hline 10 & 0.9781 & 0.9893 \\
\hline 11 & 0.9785 & 0.9879 \\
\hline 12 & 0.9816 & 0.9889 \\
\hline 13 & 0.9755 & 0.9835 \\
\hline 14 & 0.9862 & 0.9965 \\
\hline
\end{tabular}

\section{B. Wind speed changes accompanied with line fault.}

Fig.12, displayed the effect of a single line-to-ground fault (applied on phase A at bus 8 ) at $t=20$ s for a 7 cycle $(0.14 \mathrm{~s})$, with the same wind velocities in case A.

Fig.12.a, illustrate the sharp increasing in $\omega_{r}$ during the fault .The positive sequence voltage at terminals of the wind turbine (V_B15) drops to $0.59 \mathrm{Pu}$ during the fault as in Fig.12.b.

During the fault the wind-turbines generated reactive power reaches to 5 MVAR as appeared in Fig. 12.c.

The real power dropped to zero MW for some cycles as shown in Fig. 12.d. The variation in voltage of the output DC-link is shown in Fig.12. e.

The pitch angle is not displayed here because it is not influenced, due to the rotor speed does not exceed the specified speed (at point D) during the fault.

The voltage profile at each bus before and after connected the wind farm with the utility grid illustrated in Fig.13, and Fig.14, respectively.

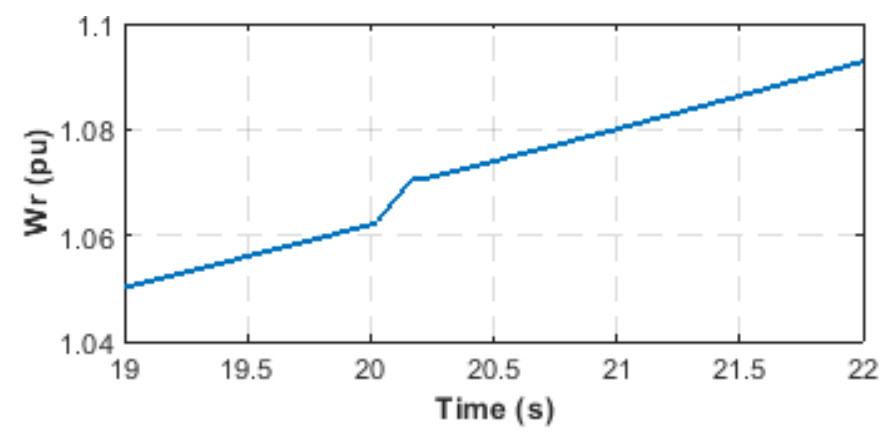

(a)

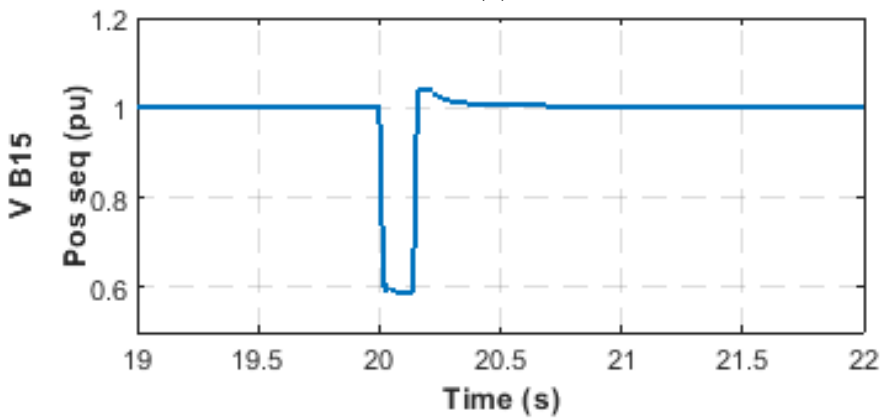

(b)

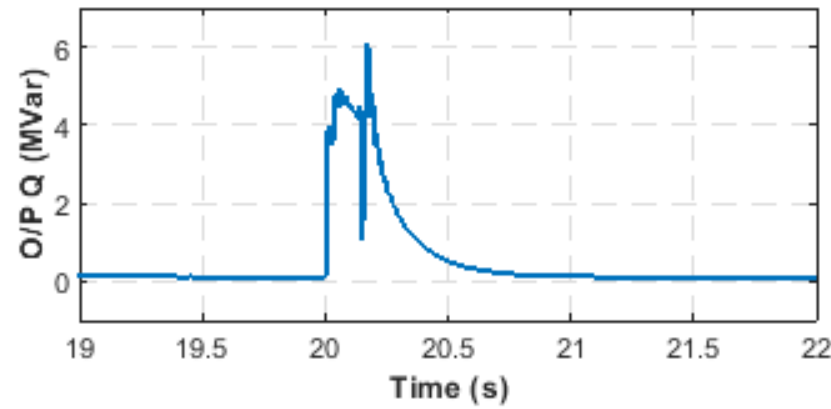

(c)

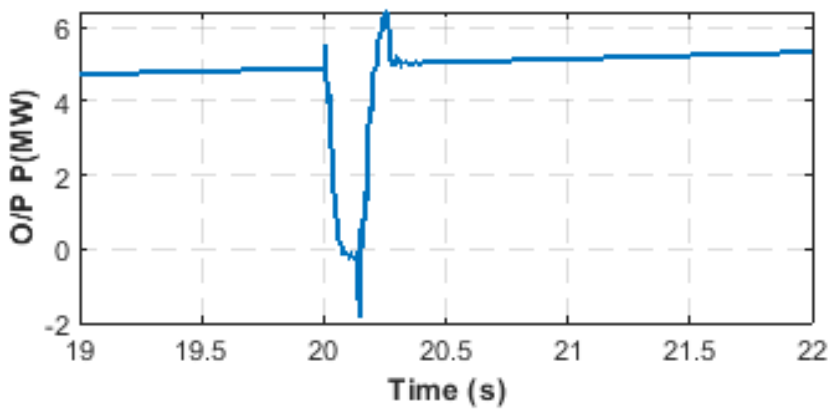

(d)

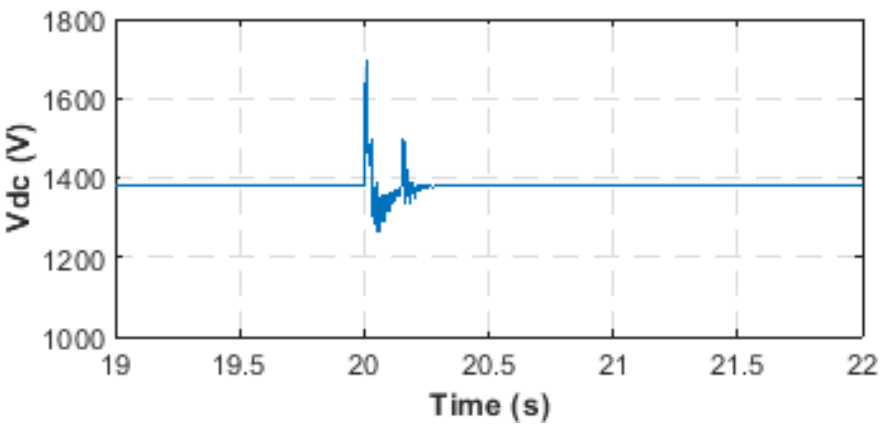

(e)

Fig. 12. Turbine reaction to Fault at bus 8 :(a) wr, (b) the voltage, (c)the reactive power, (d) the power, (e) vdc.

Published By:

Blue Eyes Intelligence Engineering and Sciences Publication (BEIESP) (C) Copyright: All rights reserved.

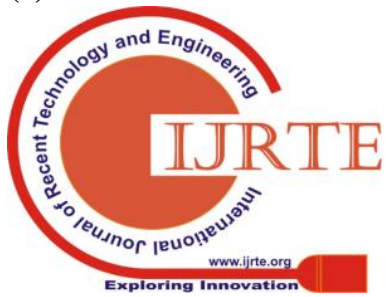




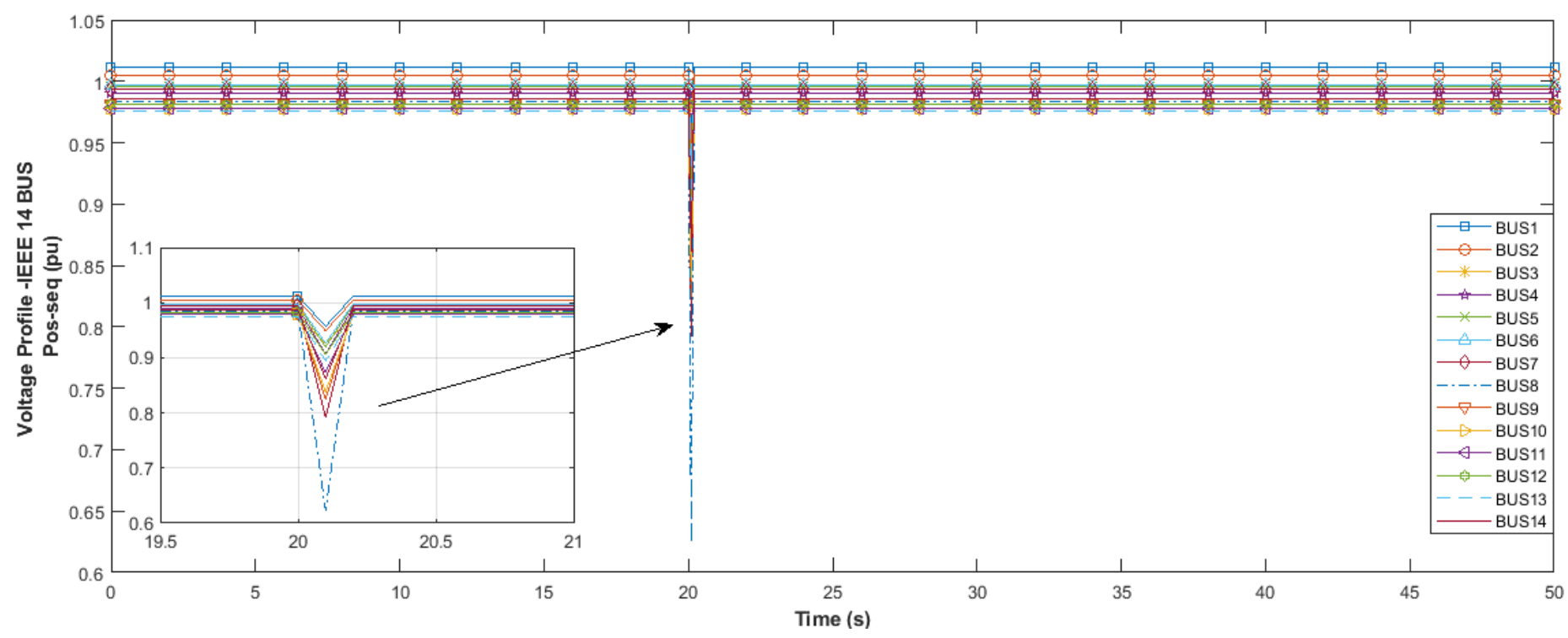

Fig. 13. The voltage profile of IEEE 14 bus system without wind farm.

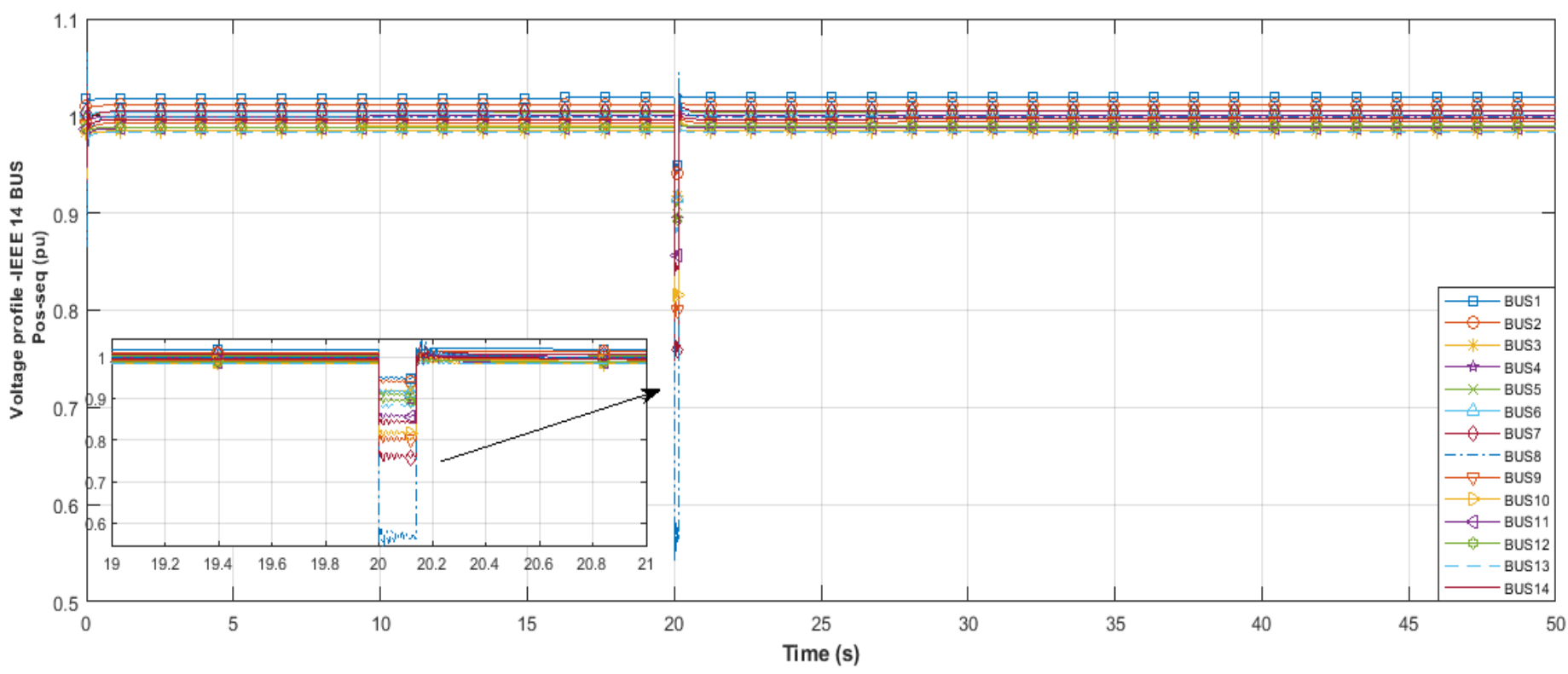

Fig. 14. The voltage profile of IEEE 14 bus system with wind farm.

From Fig.13, and Fig.14, the wind farm cannot improve the voltage profile during the fault, but it is improving in the response for coming back to the normal value of the system. It is notice that, the system arrival to nominal form without the wind frame at $\mathrm{t}=20.2 \mathrm{~s}$, But with the wind farm at $\mathrm{t}=20.14 \mathrm{~s}$ (i.e. immediately).

The system parameters for the proposed model are listed in table-II to table-IV.

Table- II: The wind turbine parameters

\begin{tabular}{|c|c|}
\hline \multirow{4}{*}{ Turbine } & Number of blades $=3$ \\
\cline { 2 - 2 } & Diameter of Rotor $=80 \mathrm{~m}$ \\
\cline { 2 - 2 } & Gear box ratio $=80$ \\
\cline { 2 - 2 } & Wind speed range $=3.5-12.1 \mathrm{~m} / \mathrm{s}$ \\
\hline
\end{tabular}

Table- III: The generator parameters

Table- IV: The filter parameters

RL Filter

\begin{tabular}{|c|}
\hline $\mathrm{R}_{\mathrm{g}}=6 \mathrm{~m} \Omega$ \\
\hline $\mathrm{L}_{\mathrm{g}}=0.6 \mathrm{mH}$ \\
\hline
\end{tabular}

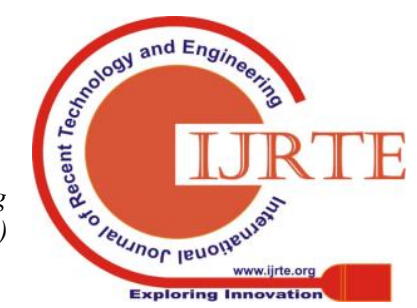




\section{CONCLUSION}

DFIG modelling, simulating and analyzing of a wind turbine with a variable wind speed have been satisfactory fulfilled. The DFIG suitability for a stable and reliable wind energy conversion system has been proved especially for a wide range of speeds to extract the electrical power. The suitable converter control mechanisms interface the public network has been demonstrated the DFIG to be more stable and efficient.

The simulation results show an excellent response of the DFIG vector control model because of this controller separate the dynamical control of reactive and real power. The reactive power can be absorbed or generated to maintain the voltage at $1 \mathrm{pu}$. The active maximum power points are tabulated and then used for applying the system control. Pitch angle $(\beta)$ is kept at zero degrees until the wind turbine velocity reaches $1.21 \mathrm{pu}$, after this point the pitch angle control will be energized even if the change is very low. that:

The hybrid (wind farm - grid) system response displayed

1) An improvement in the voltage profile even at hardly wind speed changes.

2) The fast recovery feature of the system after clearing the fault.

\section{REFERENCES}

1. Bongani Malinga, Dr. John E. Sneckenberger, Dr. Ali Feliachi, "Modeling and Control of a Wind Turbine as a Distributed Resource," IEEE, MARCH 2003.

2. Staff of Lab-Volt Ltd, "Principles of Doubly-Fed Induction Generators (DFIG) "Canada May 2011.

3. Rahab A, Senani F, Benalla H., "Direct Power Control of Brushless Doubly-Fed Induction Generator Used in Wind Energy Conversion System," International Journal of Power Electronics and Drive System (IJPEDS), 8(1): 417-433, March 2017.

4. Mohit Singh, Surya Santoso, "Dynamic Models for Wind Turbines and Wind Power Plants," NERL/SR-5500-52780, OCTOBER 2011.

5. A. Betz, "Wind Energy and its Exploitation by Windmills," Gottingen: Van-denhoeck und Ruprccht, p. 64, 1926.

6. Siegfried Heier, "Grid Integration of Wind Energy Conversion Systems,” John Wiley \& Sons Ltd, 1998, ISBN 0-471-97143-X.

7. Lubosny, Z. "Wind Turbine Operation in Electric Power Systems" Springer, Germany, 2003.

8. R. Pena, J.C. Clare, G.M. Asher, "Doubly fed induction generator using back-to-back PWM converters and its application to variable-speed wind-energy generation”IEEE Proc.-Electr. Power Appl., Vol. 143, No. 3, May 1996.

9. John Fletcher and Jin Yang, "Introduction to the Doubly-Fed Induction Generator for Wind Powe Applications” Paths to Sustainable Energy, Dr Artie Ng (Ed.), ISBN: 978-953-307-401-6, INTECH, 2010.

10. Richard Gagnon, Gilbert Sybille, Serge Bernard, Daniel Paré, Silvano Casoria, Christian Larose, "Modeling and Real-Time Simulation of a Doubly-Fed Induction Generator Driven by a Wind Turbine," Presented at the International Conference on Power Systems Transients (IPST'05) in Montreal, Canada on June 19-23, 2005, No. IPST05-162.

11. T.Ghennam,E.M.Berkouk," Modeling and control of a Doubly Fed Induction Generator(DFIG) Based Wind Conversion System", IEEE,Laboratoire d'Elctronique de Pussance,Algeria, March 18-20,2009.

12. Ekanayake, J. B., Holdsworth, L., Wu, X. and Jenkins, N. (2003) Dynamic modelling of doubly fed induction generator wind turbines, IEEE Transactions on Power Systems, 18 (2), 803-809

13. Wei Qiao, Member, IEEE" Dynamic Modeling and Control of Doubly Fed Induction Generators Driven by Wind Turbines" IEEE/PES Power Systems Conference and Exposition, 2009. PSCE '09.

14. S. Kodsi, and C. Ca nizares, "Modeling and Simulation of IEEE 14 Bus System with Facts Controllers," Technical Report, 2003.
15. A. Feijóo, On PQ models for asynchronous wind turbines, IEEE Trans. Power Syst., vol. 24, no. 4, pp. 1890-1891, Nov. 2009.

\section{AUTHORS PROFILE}

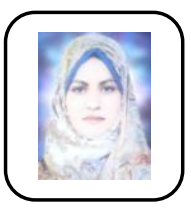

Sally El-Tawab received the B.Sc. (2013) from Al-Azhar University. Currently she is Teaching Assistant in the Department of Electrical Engineering, Faculty of Engineering, Al-Azhar University, Egypt. Her research interests are in power system operation, power system control, power quality and renewable energy.

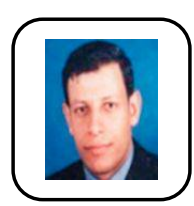

Ibrahim Nassar received the B.Sc. (1999) \&M.Sc. (2004) degrees in Electrical Engineering from Al-Azhar University. He received his $\mathrm{PhD}$ in Rostock University, Germany (2011). Currently he is Associate professor in the Department of Electrical Engineering, Faculty of Engineering, Al-Azhar University, Egypt. His research interests are in power system operation, power system control, power quality and renewable energy.

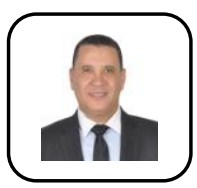

Mohammed Mehanna received the B.Sc. (1995) \&M.Sc. (2002) degrees in Electrical Engineering from Al-Azhar University. He received his PhD in Al-Azhar University, Egypt (2007). Currently he is a professor, Head of Electrical Department, Faculty of Engineering, Al-Azhar University, Egypt. His research interests are in power system operation, power system control, optimization theory, power quality and renewable energy.
Published By:

Blue Eyes Intelligence Engineering and Sciences Publication (BEIESP)

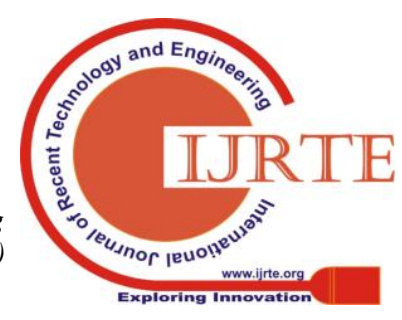

